\title{
DUALIDADE E IRONIA EM ESAÚ E JACÓ
}

\author{
ANA MARIA MEDEIROS DA COSTA \\ Universidade do Estado do Rio de Janeiro \\ Rio de Janeiro, Rio de Janeiro, Brasil
}

Resumo: O artigo aborda o tema da ironia no texto de Machado de Assis, a partir de uma leitura da psicanálise. Propõe os conceitos de narcisismo das pequenas diferenças a partir de Freud, na análise do romance Esaú e Jacó. Situa a escolha forçada como impossibilidade de escolha, nas posições dos personagens construídos nesse romance. Desenvolve como a dualidade de opostos é transposta na narrativa pela construção da ironia.

Palavras-chave: ironia no texto de Machado de Assis; narcisismo das pequenas diferenças; escolha forçada

\section{DUALITY AND IRONY IN ESAU AND JACOB}

Abstract: This article is a psychoanalytic reading of the theme of irony in Machado de Assis's work. It proposes the use of Freud's concept of "narcissism of minor differences" in the analysis of the novel Esaú e Jacó (Esau and Jacob). It also presents the "forced choice" as an impossibility of choice by the novel's characters. It further develops how the duality of opposites is transposed in the narrative by the use of irony. Keywords: irony in Machado de Assis's work; narcissism of minor differences; forced choice 
$\mathrm{P}$ areceria dar mão à regra começar um artigo evocando as afinidades entre psicanálise e literatura. Partindo de referências a Freud e Lacan, a psicanálise trata dessas afinidades com cautela, reconhecendo a precedência da literatura. Muito mais que uma precedência, diz respeito a um trato distinto dos restos da cultura, com isso de que a linguagem não dá conta, mas que pode ser usado na criação. Digamos, parafraseando Joyce e Lacan, a letra/lixo que pede ligações pede corpo e endereçamento. O trato distinto vai encontrar o psicanalista acompanhando o sujeito numa antecâmara de sua solidão, quando este perde os enlaces, confundindo-se com esses restos e tentando não naufragar. Já o escritor possui o saber das pontes, sua solidão não o desperdiça e sua letra retorna à cultura na construção de um leitor.

Arriscaremos um trânsito tecido com linhas tênues, ousando a entrada numa obra que reverbera ainda hoje, na multiplicidade de comentadores e críticos. Machado de Assis legou-nos uma letra aparentemente límpida, com suas histórias e personagens bem constituídos, brilhantemente construídos numa cor local e tempo histórico definido. A primeira aproximação poderia esgotar-se numa crítica de costumes, numa sociedade do Brasil em construção, na cidade do Rio de Janeiro do final do século XIX, com seus valores incertos e posições moventes. No entanto, a posição do narrador, de aproximação e distância, crítica e condescendência com seus personagens, cumplicidade com "a leitora" nas análises das situações, carrega uma forma inusitada de produção de sentidos.

É principalmente pela posição do narrador que se abre uma continuidade entre individual e coletivo, transformando a obra do autor em universal e atemporal. Nessa continuidade é possível passar-se de posições individuais, a um trânsito no discurso social, fazendo com que a estrutura em causa nos mesmos não se diferencie. Lacan, em publicação que se dedica a analisar o tema da angústia, situa essa condição como uma continuidade moebiana. Essa análise toma como suporte uma referência à matemática, que propõe a apresentação de um espaço topológico em que é possível passar do interno ao externo sem que se representem descontinuidades. No Seminário A Angústia, ministrado em Paris em 1963 e publicado no Brasil em 2005, Lacan desenvolve detidamente como na angústia, por exemplo, o sujeito se encontra prisioneiro do que Freud denominou de Umheimlich, um estranho, mas ao mesmo tempo familiar, que nos habita. $\mathrm{Na}$ angústia o estranhamento vindo do exterior incide sobre representantes pulsionais que o sujeito não reconhece como sendo seus. Adiante desenvolveremos mais detidamente o tema do pulsional. Assim, essa exterioridade desperta algo de um íntimo 
desconhecido, provocando angústia. Em muitos casos o que projetamos no outro resulta de algo que desconhecemos em nós mesmos. Pensar nisso como sendo um topos, um lugar, que diz também de nosso mais íntimo interessa à psicanálise. Ele é responsável por muitas identificações ao outro, no qual projetamos algo que não gostamos de reconhecer como próprio. Lacan desdobrou a análise freudiana sobre o sentimento do estranho, situado na expressão Unheimlich, utilizada por Freud. Essa expressão diz do sinistro, do estranho, mas contém heim, a denominação de casa, do íntimo. Segundo Lacan:

Digamos que, se essa palavra tem algum sentido na experiência humana, é o da casa do homem. Deem à palavra "casa" todas as ressonâncias que quiserem... O homem encontra sua casa num ponto situado no Outro para além da imagem de que somos feitos. ${ }^{1}$

Para a psicanálise, o tema da dualidade resulta dessa condição expressa nesse estranho familiar. Ele se apresenta em fenômenos do duplo, tal como a literatura já trabalhou em tantas obras, veja-se o conto de Edgar Allan Poe "William Wilson". Apresenta-se também no estranhamento que provoca angústia, ou mesmo nos jogos de linguagem, tal como na ironia. Assim, faz parte de produções de imagens, bem como de produções simbólicas, contidas em expressões linguageiras.

Machado de Assis, em sua obra, trabalha com elementos próprios a essa continuidade moebiana, passando de temas aparentemente restritos ao indivíduo, na sua intimidade da família, às suas projeções nas relações sociais. Essa posição faz passar, por meio de seus personagens, elementos resultantes da relação do sujeito com a linguagem, esse Outro situado por Lacan, numa abertura a construções simbólicas, que irão constituir tanto identificações imediatas, quanto enigmas por meio de construções alegóricas. Desde a produção de ironia contida na conversa do narrador com "a leitora", como se fosse uma literatura restrita às mulheres; até os elementos da literatura universal, com os quais Machado dialoga.

Esaú e Jacó é o penúltimo livro de Machado de Assis, sendo que nele o autor desenvolveu com mestria os principais elementos que temperam sua obra. Entre eles, a se destacar, está a ironia. Só para lembrar: ironia vem do grego e significa dissimulação. Nesse aspecto, participa do movimento mais geral da linguagem, de se suspender ou de se negar a si mesma.

${ }^{1}$ LACAN, O seminário. Livro 10. A angústia, p. 58. 
Corriqueiramente é tomada como uma forma de afirmar pela negativa, como encobrindo, e ao mesmo tempo revelando, uma dupla intenção. Nesse sentido, serve para as construções de duplos que encobrem, trazendo formas de subtextos, dicotomias, ambiguidades. Essas condições se particularizam em Machado, na medida em que nele a ironia participa do humor. Assim, não é por qualquer expressão que essa duplicidade se evidencia.

Do ponto de vista da psicanálise, podemos dizer que a ironia se situa na forma como a pulsão é tomada na língua, passando duplicidades nos registros de idealização e rebaixamento, ou mesmo sexualidade e agressividade. $\mathrm{Na}$ clínica psicanalítica reconhecemos que a duplicidade indica uma convivência de opostos nas formações subjetivas, sem que esses opostos sejam explicitados. A referência do sujeito à idealização, por exemplo, contém seu oposto, na medida em que muitas vezes ele precisa rebaixar-se para manter um ideal como inatingível. Já no campo da sexualidade, as pulsões trazem junto a duplicidade de conter, ao mesmo tempo, erótica e agressividade, muitas vezes somente aplacadas por um amor sublimado. Assim, o tema da duplicidade e da ambiguidade contém, em si mesmo, uma construção de opostos.

$\mathrm{Na}$ referência ao humor cabe lembrar, tal como assinalado por Freud, que encontramos nele diferentes produções. Quando se fixa no cômico, situa um jogo especular em que alguém ri do outro, enquanto um objeto risível. No caso, é a uma imagem rebaixada e colocada no outro que o sujeito visa. Ou pode produzir um dizer pelos jogos simbólicos com a linguagem, desenvolvido pelo autor no tema do chiste e suas relações com o inconsciente. Neste último caso, o gozo no riso não se cola à imagem do outro, situando-se nas construções que o trato com a linguagem permite. No primeiro caso, o sujeito projeta no outro algo desagradável que não quer reconhecer em si. No segundo, o humor toma a linguagem como referência simbólica, constituindo uma cumplicidade com o outro no riso compartilhado.

A ironia machadiana participa desta última condição do humor, não se fixando num traço corpóreo risível do outro. Esta condição de transcender a dicotomia eu/outro está presente em seu estilo, na medida em que ele transpõe um dizer, com seus efeitos, para muito além da novela criada. É isso que permite que construções que trazem uma dúvida no seu sentido produzam enigmas para leitores e crítica literária de todos os tempos. Um dos maiores representantes dessa condição enigmática é imortalizado na personagem Capitu, do romance Dom Casmurro. Assim, a duplicidade, ou mesmo a ambiguidade, não provoca efeitos complementares, de um espelho 
que projeta no outro algo desagradável, senão que se precipita nos jogos de linguagem que cada personagem faz passar.

Se a ironia resulta de um subtexto não explícito, implicando o jogo com duas ideias aparentemente contraditórias, encontramos em Esaú e Jacó sua forma mais acabada, plasmada na encenação de dois personagens - os gêmeos Pedro e Paulo. A passagem da Monarquia à República, encarnada nas posições de Pedro e Paulo, revela uma discordância apensa a um narcisismo de pequenas diferenças, em que os interesses pessoais se misturam aos jogos políticos. Como um gêmeo, Paulo republicano é idêntico a Pedro monarquista, revelando que a passagem de um estado a outro, nessa época social brasileira, era operada por disputas de grupos políticos centrados unicamente na busca do poder, igualando-se na sua base. Os personagens que mais evidenciam esses jogos são Batista e d. Cláudia, dois oportunistas, pais de Flora, esta sendo a mulher disputada pelos gêmeos e que é apaixonada pelos dois, incapaz de escolher por um deles, perdida entre suas semelhanças. Temos também Santos, pai dos gêmeos, que de sua origem humilde fez fortuna com usura, tornando-se banqueiro, representante de uma classe em ascensão que se torna dominante, entusiasmado pela promessa de grandeza entrevista em seus descendentes, anunciada pela "cabocla do Castelo" e confirmada por seu amigo espírita. Natividade, mãe dos gêmeos, e Flora, a mulher disputada por eles, contrabalançam essa dinâmica por seu amor pelos dois. Destacam-se como esse campo do privado, que as mulheres representavam. Por último, o Conselheiro Aires, diplomata aposentado, homem cético, espécie de testemunha, um narrador como um duplo do autor, em cujo caderno - depois de sua morte - foi encontrada a história que lemos.

Interessa-nos destacar alguns elementos que fazem esta obra transcender o tempo e a cor local. Eles estão na construção narrativa, que fisga para além do sentido da história contada. A ironia machadiana, assim como Aires, não toma posição na disputa Pedro/Paulo, no que essa disputa força a uma escolha. A ironia revela que a escolha alienada à disputa é narcísica, ou seja, faz parte das pequenas diferenças inconsistentes, que despencam em posições moventes, de acordo com os destinos do poder. A mestria de Machado está em situar na ironia uma posição terceira como saída narrativa.

Transitemos um pouco nesse tema da escolha a partir da psicanálise. Lacan o abordou na referência à escolha forçada, fazendo parte da captura do sujeito na alienação à linguagem. Para Lacan, o tema da alienação à linguagem constitui uma condição inescapável, encerrando as escolhas que fazemos dentro de um universo restrito. A linguagem é primeiramente situada 
naqueles cuidadores da criança, que a transmitem partindo desse universo privado, com seus interesses e formas de interpretação do mundo. O uso da linguagem e construções de sentido partem disso, para depois transpor esse uso a relações mais amplas, constituintes da cultura. No entanto, a forma dessa transmissão privada acompanha o sujeito em sua vida, fazendo com que as condições possíveis de escolha, numa abertura simbólica, sejam reduzidas. Encontramos traços dessa forma de alienação, que diz de uma impossibilidade de escolha diferente, nos elementos utilizados pelo sujeito em expressões corriqueiras. Desde escolhas banais, até escolhas viscerais, implicando uma perda mais radical, do tipo "a bolsa, ou a vida". O que significa que, seja qual for a escolha, algo valioso ou mesmo radical é perdido (no caso do exemplo, quando se tratar da vida). Nesse sentido, a questão da escolha, na alienação, opera com uma dimensão de perda. Perda, esta, dizendo respeito à posição interpretativa que as relações amorosas imprimem inicialmente na vida. O que significa que, ao tomar uma posição, algo da captura narcísica se perde para o sujeito, abrindo a dimensão do desejo, na medida em que este é movido por algo que lhe falta, que não mais encontrará ao precisar transpor seu universo privado.

O narcisismo das pequenas diferenças introduz a dimensão da escolha como uma convocação à agressividade: "ou eu, ou tu". A diferença não surge como traço separador, mas como duplo especular complementar. Pedro e Paulo são figuras dependentes uma da outra e, nesse sentido, prisioneiras do espelho, convocando agressividade (a disputa que já começa no ventre da mãe). Seus traços somente tomam relevância e se mantêm na comparação com uma imagem situada no outro. Nos ínfimos episódios, tal como quando Pedro comprou uma gravura de Luís XVI e Paulo "quis ter igual fortuna" e comprou um Robespierre. No fim das contas, o que poderia ser a diferença de cada personagem acaba reduzindo-se e encerrando-se numa rivalidade especular. Assim, essa espécie de narcisismo é um norteador das posições de cada um, sendo a mola diretora do laço vigente, abarcando não somente a encarnação nos gêmeos, espraiando-se nas diferentes situações e personagens.

Se a rivalidade leva a uma necessidade de escolha, tematizada por uma aparente diferença encerrada no viés da agressividade (ou... ou), Natividade e Flora expressam sua outra face, reconhecendo as semelhanças. Como mãe, Natividade demanda a junção dos filhos. Já Flora, em seu amor pelos dois, reconhece que eles se mantêm da união em que se completam, como na frase: "Ora bem, acabas de ver como Flora recebeu o irmão de Pedro, tal qual recebia 
o irmão de Paulo". Ela representa a impossibilidade de escolha nas construções de duplos. Aires situa a moça como "inexplicável". Eis como ele a descreve:

Quem a conhecesse por esses dias, poderia compará-la a um vaso quebradiço ou à flor de uma só manhã, e teria matéria para uma doce elegia. Já então possuía os olhos grandes e claros, menos sabedores, mas dotados de um mover particular, que não era o espalhado da mãe, nem o apagado do pai, antes mavioso e pensativo, tão cheio de graça que faria amável a cara de um avarento. Põe-lhe o nariz aquilino, rasga-lhe a boca meio risonha, formando tudo um rosto comprido, alisa-lhe os cabelos ruivos, e aí tens a moça Flora. ${ }^{3}$

Tanto a "flor de uma só manhã", quanto a "inexplicável" Flora dizem da beleza dessa personagem, cuja construção poética faz parte da galeria das personagens femininas machadianas, tal como a Capitu imortalizada nos "olhos de ressaca". Personagens que trazem a condição de serem "faladas", plenas de uma ausência que as embeleza enigmaticamente. É em Flora que a impossibilidade de escolha, pela impossibilidade de distinguir a diferença entre os gêmeos, assume um tal paroxismo que a leva a adoecer e a morrer. Nela se realiza a "imagem machadiana", no sentido que Walter Benjamin dá de imagem dialética, como criação alegórica. Por meio dela o autor faz passar o que se fixa nesse laço sintomático, que impossibilita qualquer tomada de posição outra que não a escolha forçada, tal como a definição que Freud dá a uma escolha do sintoma, enquanto alienada a uma condição do discurso. Digamos que Flora é a construção maior da ironia machadiana, nomeada como destino, no título dado ao romance - Esaú e Jacó -, definição oracular de um texto bíblico, cuja engrenagem situa um destino de relações.

Destacamos também as construções irônicas contidas no capítulo VI, que transmitem a ambiguidade enquanto efeito do narcisismo dos personagens. Nesse capítulo, a ambiguidade faz parte da posição de cada um na acolhida da gravidez de Natividade. Esta personagem transita entre o desejo de ser mãe e a perda que essa condição lhe traria no lugar social que conseguira. Lá se iam os bailes da alta roda, posição conseguida por ter um marido capitalista. Machado transita entre a posição narcísica da personagem, com o brilho social conseguido, e a vinda de um filho, situação em que precisaria abrir mão da "folga". O capítulo encerra com a interpretação maior

${ }^{2}$ ASSIS, Esaú e Jacó, p. 951.

${ }^{3}$ Idem, p. 914. 
do personagem de Santos, mirando-se em sua magnífica casa na enseada de Botafogo, trazendo uma estatueta de Narciso no meio do jardim:

A casa descobria-se a distância, magnífica; Santos deleitou-se de a ver, mirou-se nela, cresceu com ela, subiu por ela. A estatueta de Narciso, no meio do jardim, sorriu à entrada deles, a areia fez-se relva, duas andorinhas cruzaram por cima do repuxo, figurando no ar a alegria de ambos. A mesma cerimônia à descida. Santos ainda parou alguns instantes para ver o coupé dar a volta, sair e tornar à cocheira; depois seguiu a mulher que entrava no saguão. ${ }^{4}$

Aqui vemos o destino dos filhos, remetendo cada um a contemplar-se no espelho a que se reduziam, enquanto efeito do laço social a que pertenciam. Também por essa razão Natividade busca a cabocla do castelo, para que lhe diga o grande destino que os filhos teriam, como continuidade de sua imagem.

Assim, as criações machadianas operam de uma maneira peculiar com a construção de ambiguidades pessoais, dualidades e duplos. Encontramo-las ao longo de sua obra, tanto nos romances, quanto nos contos. Destes últimos, destaco "O espelho", no seguinte trecho: "Cada criatura humana traz duas almas consigo: uma que olha de dentro para fora, outra que olha de fora para dentro...". ${ }^{5}$

O primor desse conto diz respeito a constituir um certo testemunho da planura da alma humana, sua condição de encarnar-se nos objetos, de tal maneira que os mesmos a espelham e a conformam. Muitas vezes, torna-se difícil diferenciar se é nossa alma (as condições com que se constroem nossos valores) que cria os objetos, ou se são os objetos que criam nossa "alma". Em todo caso, essa questão somente expressa uma soldadura entre nossa imagem e os objetos que a revestem, por onde despedaçamos e dispersamos nossas imagens, para dar-lhes sustentação e, com isso, dar consistência à evanescente representação de nosso corpo.

No conto, Machado de Assis narra o testemunho do personagem Jacobina quando, num episódio de sua juventude, fora nomeado alferes da guarda nacional. A ironia machadiana constrói a situação de uma maneira, ao mesmo tempo, jocosa e tensionante. O que ele reproduz é a tendência que temos de confundirmos nossa condição de existência com as funções sociais situadas na vestimenta, na medida em que ela encarna o olhar do outro. Sem a farda a mostrar esse olhar, o personagem do alferes desaparece do espelho e,

${ }^{4}$ Idem, p. 890.

${ }^{5}$ ASSIS, O espelho, p. 341. 
com isso, perde a consistência de seu corpo. Nesse conto temos uma outra forma de trabalho com o duplo. Diferente de Pedro e Paulo, o personagem do alferes está no espelho, prisioneiro do olhar que o conforma. Ou seja, Jacobina não tem nenhuma distância da imagem que a farda reveste. Nos dois casos no narcisismo das pequenas diferenças, situado no duplo; ou na colagem ao olhar do outro do espelho -, Machado constrói personagens que se confundem e se misturam na passagem privado/público. É desse modo que sua narrativa interpreta uma determinada forma de laço, transcendendo o âmbito da novela e situando a posição do sujeito em suas fragilidades constitutivas, que duplicam também fragilidades e irresoluções sociais. Assim, mesmo que Machado tenha interpretado, de forma magistral, um certo retrato de época, o que ele transmite vai muito além da redução a um tempo histórico definido.

Para concluir, transitamos na referência à dualidade em Esaú e Jacó, abordando o que a psicanálise trata como narcisismo das pequenas diferenças, que situa posições, aparentemente opostas, funcionando como imagens que se complementam, na manutenção de uma mesma posição subjetiva. Tratamos, também, como a ironia, nos jogos de linguagem construídos por Machado de Assis, traz uma saída diferente do que o aprisionamento no espelho, permitindo ao leitor transitar como uma posição terceira, que não reenvia para a dimensão narcísica, senão que a interpreta.

\section{Referências}

ASSIS, Machado de. Dom Casmurro. In: Obra completa. Rio de Janeiro: Nova Aguilar, 1992.

Esaú e Jacó. In: Obra completa. Rio de Janeiro: Nova Aguilar, 1992.

O espelho. In: Obra completa. Rio de Janeiro: Nova Aguilar, 1992.

BENJAMIN, Walter. A imagem de Proust. In: Magia e técnica, arte e política. Obras escolhidas, vol. 1. São Paulo: Brasiliense, 1985.

FREUD, S. El chiste y su relación con el inconsciente. In: Obras completas. Madrid: Biblioteca Nueva, 1973.

. El siniestro. In: Obras completas. Madrid: Biblioteca Nueva, 1973.

- Psicología de las masas y análisis del yo. In: Obras completas. Madrid: Biblioteca Nueva, 1973.

LACAN, J. O seminário. Livro 10. A angústia. Rio de Janeiro: Jorge Zahar Ed., 2005. - O seminário. Livro 11. Os quatro conceitos fundamentais da psicanálise. Rio de Janeiro: Jorge Zahar Ed., 1985.

POE, E. A. William Wilson. In: Contos escolhidos. Rio de Janeiro: Globo, 1985. 
ANA MARIA MEDEIROS DA COSTA é professora da Pós-graduação em Psicanálise da Universidade do Estado do Rio de Janeiro; psicanalista membro da Associação Psicanalítica de Porto Alegre. Autora dos livros A ficção do si mesmo (1998), Corpo e escrita. Relações entre memória e transmissão da experiência (2001), Tatuagem e marcas corporais (2003), Litorais da psicanálise (2015). E-mail: medeirosdacostaanamaria@gmail.com.

Recebido: 17.02 .16

Aprovado: 10.06 .16 